\title{
Electricity Generation Using a Hybridized Zeolite Adsorption Heat Pump and Heat Engine
}

\author{
Linus Kweku Labik $^{1}$, Bright Kwakye-Awuah ${ }^{1}$, Baah Sefa-Ntiri ${ }^{2}$, Eric Kwabena Kyeh Abavare ${ }^{1}$, Isaac Nkrumah ${ }^{1}$ \\ \& Craig Williams ${ }^{3}$ \\ ${ }^{1}$ Department of Physics, Kwame Nkrumah University of Science and Technology, Kumasi, Ghana \\ ${ }^{2}$ Department of Physics, University of Cape Coast, Cape Coast, Ghana \\ ${ }^{3}$ Faculty of Science and Engineering, University of Wolverhampton, Wolverhampton, WV1 1LY, United \\ Kingdom
}

Correspondence: Linus Kweku Labik, Department of Physics, Kwame Nkrumah University of Science and Technology, Kumasi, Ghana. Tel: 233-26-232-6483. E-mail: linuslabik@gmail.com

Received: June 26, 2020

Accepted: July 3, 2020

Online Published: July 31, 2020

doi:10.5539/apr.v12n4p75

URL: http://dx.doi.org/10.5539/apr.v12n4p75

\begin{abstract}
The use of adsorption in Thermal Energy Storage has gained considerable research interest of late. Some applications have focused on the use of TES for transformation of low temperature heat in applications such as cooling and heating. Zeolite and water have been studied as suitable materials. Their characteristics as environmentally friendly materials and high affinity makes them conspicuous. The unique properties of zeolites to hold adsorbed water/heat with very minimal loss is also significant. With the aid of a dynamo, a Stirling engine as heat engine and the adsorption energy storage system serving as heat pump was used to generate electricity. The relationship between electricity generation and temperature was investigated. The obtained average temperature and pressure of the zeolite - water adsorption heat pump was also compared with the basic adsorption cycle.
\end{abstract}

Keywords: Thermal Energy Storage, Stirling Engine, Zeolite, Adsorption, Electricity Generation

\section{Introduction}

Energy is very crucial to the economic prosperity of a country as well as vital to their technological advancement. Un- fortunately, an overeliance on fossil fuels has the dire consequences of an unsustainable demand and environmental catastrophe. The unpredictability of supply, demand and price contribute to global political tensions (Dinçer \& Rosen, 2011).

$82.5 \%$ of Ghanaians as at 2016 had access to electricity although not constant (Kumi, 2017). "Dumsor", a Ghanaian term to describe the erratic supply of power, engulfed the country from 2012 to 2015 . It is reported to have cost US\$ 2.1 million and is attributed to loss of commercial and industrial production (Kumi, 2017). Power supply issues in Ghana is also due to the heavy reliance on hydro and fossil fuel based thermal plants with a mix of $42.79 \%$ to $57.21 \%$ (Kumi, 2017).

The development of alternative renewable energy sources can contribute to ameliorating these challenges. This should provide secure, efficient and environmentally friendly energy supply system to meet demand. It is imperative that they meet future energy needs and cheaper than conventional technologies.

Thermal Energy Storage (TES) is a viable alternative to bridging the energy demand and supply gap. Thermal energy is stored when a material is heated, cooled, vaporised or solidified (Dinçer \& Rosen, 2011). The stored energy is then released when the process is reversed. TES has received considerable interest and currently a subject of many researches. It can serve as an efficient, reliable, cheaper and environmentally benign energy source. Coupling with other thermal systems can contribute to increase in system efficiency and reliability. Good TES systems should permit minimum thermal losses and high extraction efficiencies of stored energy (Dinçer \& Rosen, 2011). Adsorption Thermal Energy Storage (ATES) a variant of TES employs the sorption process for energy storage.

In ATES, the adsorption and desorption processes occurring between an adsorbate and an adsorbent is exploited. Thus, when previously adsorbed fluid is desorbed by the adsorbent, thermal energy is stored. The reverse leads to 
an exothermic reaction releasing the stored energy. The separation of the adsorbate and adsorbent ensures the storage of energy without any loss (Fernandes, Brites, Costa, Gaspar, \& Costa, 2014). The energy is stored as potential and not as latent or sensible heat. Thus, renewable energy sources like solar and geothermal can be employed. This system can provide additional benefits for waste heat recovery in domes- tic, industrial and commercial applications. This also provides benefits to the environment in the reduction of thermal pollution.

Several systems use the adsorption cycle for heat and cold production (Cacciola \& Restuccia, 1995). The adsorbent - adsorbate pair used in such systems are critical. Although a high sorption capacity of the adsorbent is desired, other factors do matter (Aristov, 2013). A great number of natural and synthetic adsorbents are being studied for optimum performance. Common adsorbent - adsorbate pairs used in ATES include zeolite - water, activated carbon - methanol, silica gel - water and carbon - ammonia (Demir, Mobedi, \& Ülkü, 2008).

Zeolites are aluminosilicates which have a basic $\mathrm{SiO}_{4}$ - and $\mathrm{AlO}_{4}$-tetrahedral unit with different structures (Mgbemere, Ekpe, \& Lawal, 2017). These basic units are linked by a shared oxygen atom. Some properties of the zeolite structure make them well suited for applications in ATES. They have large adsorption capacities and significantly reduce the storage weight (4 to 5 times) (Tchernev, 2001). They also thermally stable over a large temperature range (Auerbach, Carrado, \& Dutta, 2003). This stability can be varied by increasing or decreasing their Si/Al ratio (Mgbemere, Ekpe, \& Lawal, 2017). Several challenges are associated with zeolite use - availability and cost of obtaining primary source silica and alumina (Mgbemere, Ekpe, \& Lawal, 2017). Synthesis of zeolites using raw materials such as kaolin, fly ash and bauxite have gained considerable interest.

A novel hybridised system comprising a heat pump and a heat engine is used to generate electricity. Incorporating a zeolite-water pair ATES, a stirling engine coupled with a dynamo produces electricity. The stirling engine serves as the heat engine and its external heat source is the ATES system. The ATES system can utilise either a renewable thermal energy source or waste heat.

The stirling engine runs based on two isothermal and tow isochoric thermodynamic processes (Hoegel, 2014). The thermal expansion or compression in the hot and cold cylinders when heat is applied moves the pistons. The pistons joined to the flywheel provide mechanical energy to rotate the rotor of the dynamo.

Principle of operation A heat pump in transferring heat from a lower temperature to a high level uses work as input (Chwieduk, 2012). A heat engine's function is to generate work with input from a heat source (Chwieduk, 2012). Thus, a heat engine using heat from a high temperature heat source to generate work. An amount of degraded heat is then released to the heat sink. Thus, fulfilling the Kelvin - Plank statement of the inability of a heat engine like a Stirling engine to achieve 100\% thermal efficiency (Dinçer \& Rosen, 2011). Thermal efficiency of a Stirling cycle can be calculated using the Carnot cycle's givenas:

$$
\eta=1-\frac{T_{c}}{T_{h}}
$$

A Stirling engine operates as in (Güven, Bedir, \& Anlaç, 2019; Hoegel, 2014) similar to the Rankine cycle. An external heat source is used to generate mechanical energy for work. A Stirling engine generally comprises a hot and cold cylinder and a regenerator. Air acting as working fluid is moved between the cylinders causing expansion and compression. The opposite movements of the pistons are aided by the phase difference determined by the crank mechanism.

The heat pump acts as the external heat pump for the Stirling engine. The crank mechanism is connected by a rubber band to the rotor of a dynamo. This dynamo generates electricity as the crank mechanism rotates. The heat pump utilises TES employing zeolite and water as working pair.

TES is categorised into three based on how heat energy is stored (Scapino, Zondag, Bael, Diriken, \& Rindt, 2017). Sensible heat storage utilises the temperature differences of the storage media. Latent heat storage utilises phase changes as the media reacts. Sorption heat storage employs the physical and chemical bonds between the media.

Adsorption is the chemical or physical reaction resulting from the interaction of a fluid on a solid surface (Fernandes, Brites, Costa, Gaspar, \& Costa, 2014). When an adsorbent is exposed to an adsorbate, an exothermic reaction involving the release of heat occurs (Dicaire \& Tezel, 2009; Królicki, Wilk, \& Zajaczkowski, 2006). Physical adsorption is due to Van der Waals forces as adsorbate are attached to the adsorbent surface. This process is a reversible process and by applying heat, the adsorbate is desorbed. Chemical adsorption occurs through the formation of ionic or covalent bonds thus have much greater bonding forces. In this process, the materials involved lose their original state unlike physical adsorption and difficult to reverse. Repeated cycles of charging and discharging has very little effect on the performance of the adsorbent. The separation of the adsorbent and 
adsorbate also ensure little or no loss of thestored energy.

The three - dimensional framework of zeolites contains channels and voids which can be occupied by water molecules and cations. They comprise $\mathrm{AlO}_{4}$ and $\mathrm{SiO}_{4}$ tetrahedral linked by oxygen atoms. This gives a net negative charge framework allowing exchange of framework cations with others. The exchange of cations however does not affect the zeolite frame- work (Kulprathipanja, 2010). The size of a pore will determine the molecules which will access its pores and channels. Zeolite properties and functions are not only dependent on their framework and pore structure. The nature and number of charge balancing cations as well as their exchange capacity are also factors (Xu, Pang, Yu, Huo, \& Chen, 2007).

Hydrothermal synthesis of zeolites using kaolin and metakaolin as Al and Si sources have been widely successful (Gougazeh \& Buhl, 2014). Synthesised zeolites include Linde Type A, X, Y, P, 4A, NaA, KI, cancrinite, sodalite, hydroxysodalite, faujasite, phillip- site and chabazite. Kaolin is a good precursor material for zeolite synthesis due to its structure (Mgbemere, Ekpe, \& Lawal, 2017). Calcination of kaolin to convert into a more reactive metakaolin is done between $550^{\circ} \mathrm{C}$ to $950^{\circ} \mathrm{C}$.

A zeolite framework based on the arrangements and packing of the primary and secondary units can only be investigated utilising some characterisation techniques. Scanning electron microscopy (SEM) is a suitable technique for the study of the size and morphology of the zeolite crystals. SEM does not give enough information about the zeolite framework. X- ray diffraction is central in the characterisation of zeolites and used in identifying the zeolite structure. Although defects cannot be identified using XRD, the completion of zeolite crystallisation and purity can be easily determined (Auerbach, Carrado, \& Dutta, 2003; Kulprathipanja, 2010). The powder pattern of zeolites serves as unique identifiers of each zeolite type.

Infrared spectroscopy also provides information of the structure of the zeolites. The identification of double, four-, five - and six-rings within the zeolite framework. This technique utilises the unique and specific frequencies associated with the internal vibrations of group of atoms. This gives a unique spectra which serves as a fingerprint for each zeolite type.

\section{Methodology}

The synthesis of the Zeolite A used was a modification of the synthesis route of (Von-Kiti, 2016) and followed the steps as summarized in Figure 1.

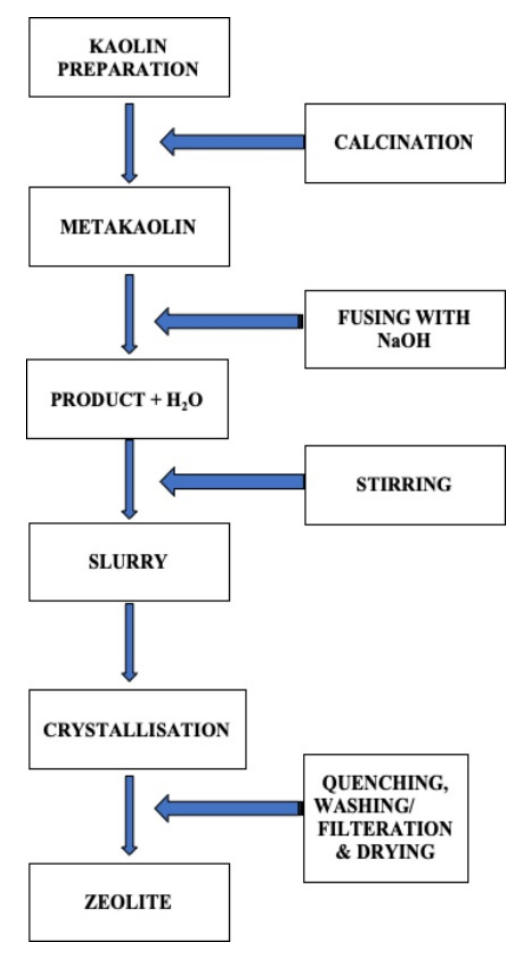

Figure 1. Synthesis process 
The preparation of this type of zeolite was carried out through the addition of $1.75 \mathrm{~kg}$ of metakaolin which was calcined at $600^{\circ} \mathrm{C}$ for an hour to $2.059 \mathrm{~kg}$ of $\mathrm{NaOH}$. Fusing of the $\mathrm{NaOH}$ and metakaolin was done for 45 minutes also at $600^{\circ} \mathrm{C}$ and crystalisation was at $105^{\circ} \mathrm{C}$ for 24 hours. The construction of an AHP system coupled with a Heat Engine to develop a trigeneration heat-to-electricity system was completed using three vessels serving as the evaporator, adsorber and condenser connected by copper tubing and valves as the AHP system and Stirling engine connected with a dynamo. This setup as in Figure 2, operates reversibly based on two cycles of adsorption and desorption.

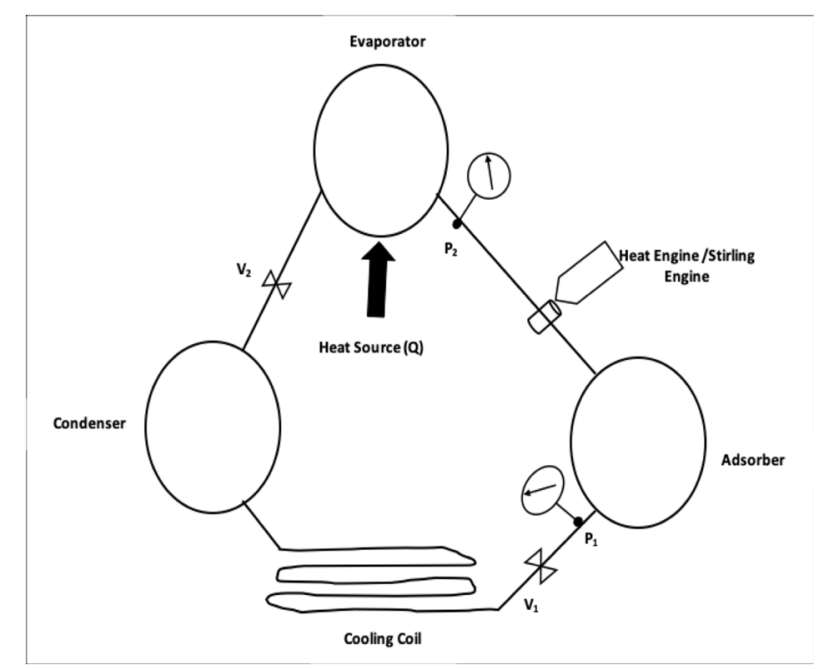

Figure 2. Schematic of the generation system

The desorption phase starts with the heating of the water in the evaporator with valve 1 opened and valve 2 closed. The heat from the LPG burner is to act as an external heat source as may be available for the system. For adsorption to occur, opening valve 1 allowed the water vapour to flow through the cooling coil into the condenser and opening valve 2 , the system gained equilibrium. Two pressure gauges were used to obtain pressure measurements for the experiments and using the temperature sensors, temperature was also measured. The heat evolved by the AHP system heats up the hot cylinder of the Stirling engine. The movement of the flywheel causes the rotation of the armature of the dynamo coupled to the Stirling engine through a rubber belt to generate electricity as in Figure 3.

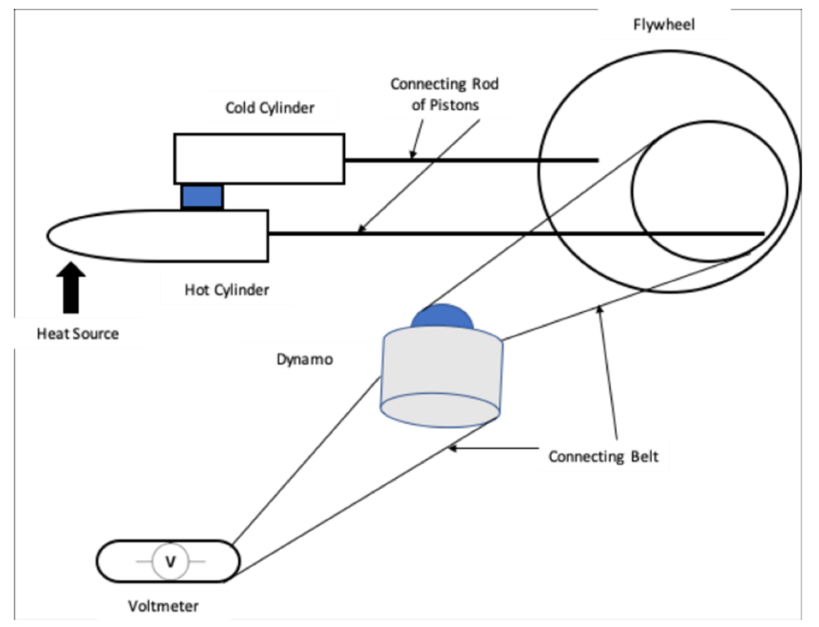

Figure 3. Shematic of the stirling engine/dynamo

The design for this system was based on the experimental parameters of Table 1 was selected based on what had been done in previous works. 
Table 1. Experimental parameters

\begin{tabular}{clclc}
\hline Experiment & Adsorbent Amount $(\mathrm{g})$ & Adsorbate Amount $(\mathrm{g})$ & Time (mins) & Repetition (no) \\
\hline 1 & 100 & 150 & 60 & 5 \\
2 & 200 & 300 & 60 & 5 \\
3 & 300 & 450 & 60 & 5 \\
4 & 400 & 600 & 60 & 5 \\
5 & 500 & 750 & 60 & 5 \\
\hline
\end{tabular}

\section{Results}

The characterisation of zeolites is integral in research (Kulprathipanja, 2010). The combination of characterisation techniques provides sufficient details of the zeolite framework. Further development of zeolites for specific needs and commercialisation is dependent on these.

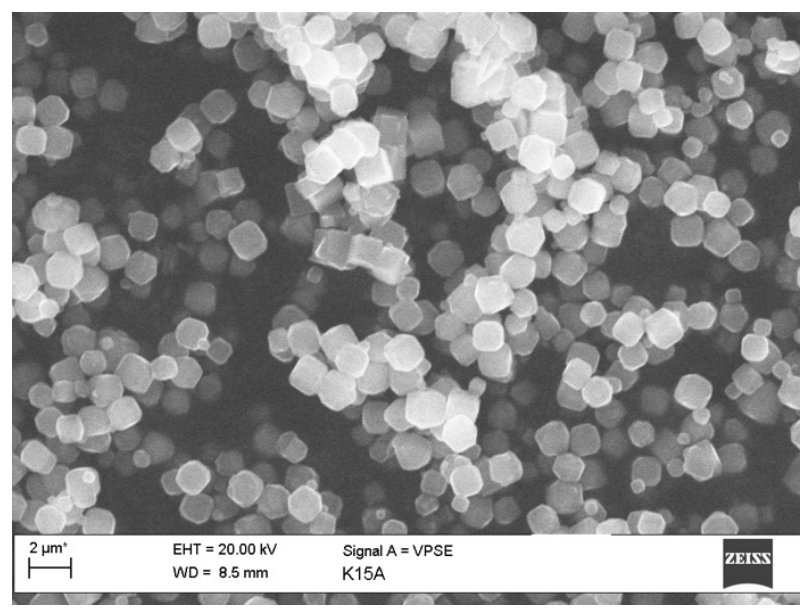

Figure 4. Scanning Electron Micrograph of Zeolite A synthesized from Wassa Kaolin

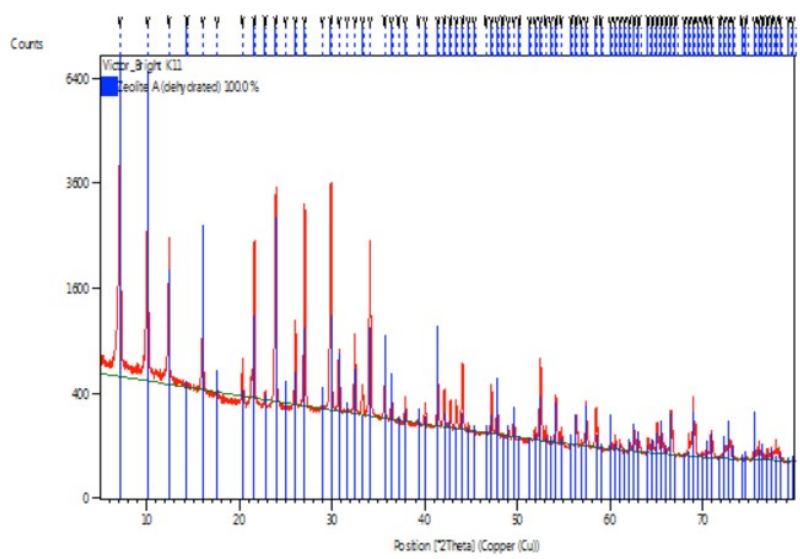

Figure 5. X-ray diffractograph of dehydrated/charged Zeolite A synthesized from Wassa Kaolin

Scanning electron microscopy (SEM) enables the determination of the size and morphology of the zeolite synthesised. The micrographs obtained (Figure 4) showed the cubic morphology associated with Zeolite A (Mgbemere, Ekpe, \& Lawal, 2017). There are no observable differences between zeolites synthesised from reagents and raw materials. Although the absence or presence of quartz maybe accounted for due to the source material as in (Kwakye-Awuah, Labik, Nkrumah, \& Williams, 2014) and (Von-Kiti, 2016). These used reagents and kaolin and bauxite as source materials respectively.

The observed characteristics of the XRD (Figure 5) showed patterns which appear at lines similar to the standard pattern of Zeolite A. The first three distinct peaks were observed at $7.12^{\circ}, 12.39^{\circ}$ and $16.04^{\circ}$. Maximum peak intensities compared favourably with (Jha \& Singh, 2016). The diffractogram showed the zeolite synthesised was 
$100 \%$ crystalline. For application such as TES, it is important that zeolites maintain their structural integrity. Comparing with (van Hooff \& Roelofsen, 1991), the observed diffraction lines had very little changes to lead to a structural collapse. The positions, intensities and shapes of peaks are basic for a diffraction pattern (Kulprathipanja, 2010). The size and shape of the unit cell of the zeolite framework determine the peak positions. Dealumination of zeolites maybe observed by the shifting of peaks. Averagely, Al - O distances are longer than $\mathrm{Si}-\mathrm{O}$ distances thus the shift to smaller $\mathrm{d}$ - spacings (higher $2 \theta$ ).

The FTIR spectra Figure 6 of the synthesised Zeolite A was compared with others. The vibrational modes of the sensitive external linkages as well as the insensitive internal tetrahedra are obtained from the spectra. With the $\mathrm{Si} / \mathrm{Al}$ ratio affecting the frequency of the bands, substation of aluminium for silicon atoms canes the $\mathrm{T}-\mathrm{O}-\mathrm{T}$ bond angles (Kulprathipanja, 2010). and Characteristic spectra of zeolite A was observed as compared with others. Four well-defined peaks were observed at $980 \mathrm{~cm}^{-1}, 657 \mathrm{~cm}^{-1}, 551 \mathrm{~cm}^{-1}$ and $460 \mathrm{~cm}^{-1}$. The peak at $657 \mathrm{~cm}^{-1} \mathrm{show}^{-1}$ the $\mathrm{T}-\mathrm{O}-\mathrm{T}$ vibrations of the framework. The internal vibrations of $\mathrm{Si}-\mathrm{O}$ and $\mathrm{Al}-\mathrm{O}$ appear at between $420-$ $500 \mathrm{~cm}^{-1}$ as in (Gougazeh \& Buhl, 2014). The positions of the bands are very sensitive to the structure and can also be used to determine the $\mathrm{Si} / \mathrm{Al}$ ratio based on the frequency of lattice vibrations (Robson, 2001). Asymmetric vibrations of $\mathrm{Si}-\mathrm{O}$ bonds appear at $980 \mathrm{~cm}^{-1}$ as well as stretching of the internal tetrahedral units. Internal and external symetric stretching however are not observed. Bands appearing around $650-500 \mathrm{~cm}^{-1}$ and $420-300$ $\mathrm{cm}^{-1}$ are due to external linkage vibrations. These are double four-membered rings (D4R), double five-membered rings (D5R), or double six-membered rings (D6R) and pore opening vibrations, respectively. The stretching of the asymetric bands between $1100-980 \mathrm{~cm}^{-1}$ and symmetric bands between $800-600 \mathrm{~cm}^{-1}$ of the $\mathrm{T}-\mathrm{O}-\mathrm{T}$ bond indicate increasing aluminium content. This is exhibited by a shift to lower frequencies.

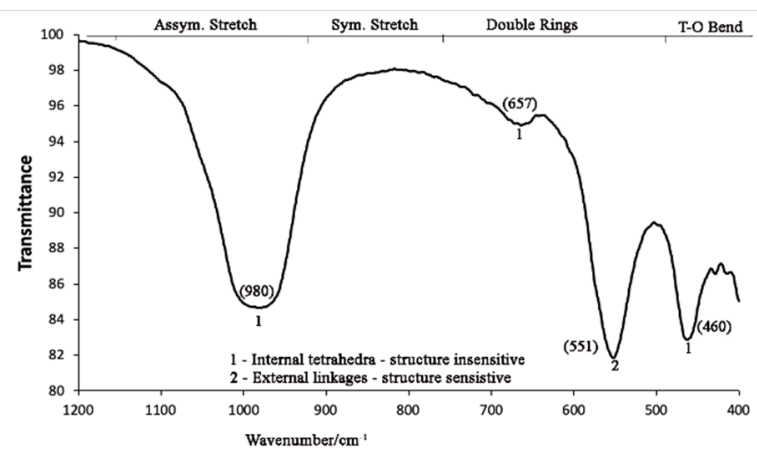

Figure 6. Fourier-Transformed InfraRed spectra showing vibrations within the framework of Zeolite A

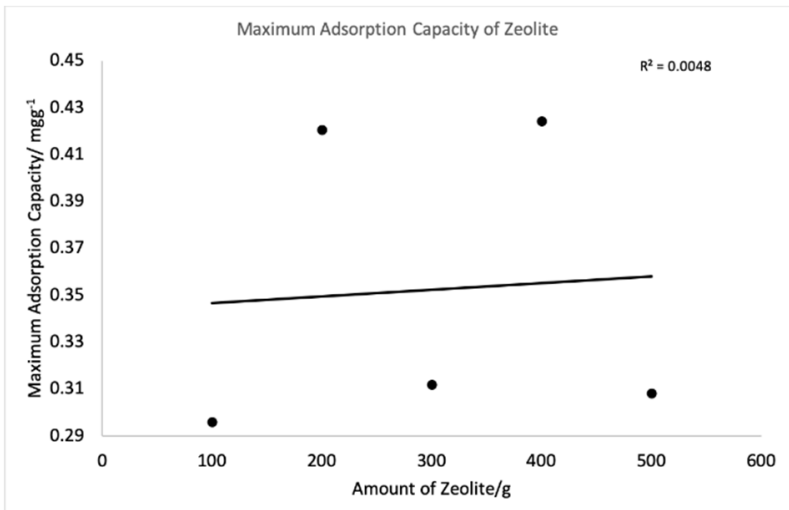

Figure 7. Maximum adsorption capacity of various amounts of Zeolite A

The sorption properties of zeolites are dependent on the bonds between the adsorbate and the zeolite adsorbent. The adsorption capacity of zeolites tend to be high due to their large surface areas. The $\mathrm{Si} / \mathrm{Al}$ ratio is inversely proportional to the hydrophilicity of the zeolite. The maximum adsorption capacity of the zeolites were obtained as in (Kot, Hui, \& Chao, 2005). The adsorption of water although increased slightly in Figure 7 with increasing zeolite quantity. Using zeolite of $100 \mathrm{~g}$ to $150 \mathrm{~g}$ of water had the least adsorption capacity of $0.29 \mathrm{gg}^{-1}$ and $400 \mathrm{~g}$ to $600 \mathrm{~g}$ of zeolite and water respectively achieved the highest of $0.42 \mathrm{gg}^{-1}$. An increasing trend is however not 
observed as with the $200 \mathrm{~g}$ and $500 \mathrm{~g}$ experiments. This cannot be accounted for by the adsorbent - adsorbate ratio as the increases are the same. Comparative desorption temperatures show the $300 \mathrm{~g}$ and $500 \mathrm{~g}$ have lower temperatures than the other experiments. Thus, lower adsorption of the adsorbates occurred in these experiments. Adsorption of water by the zeolite is also dependent on contact time. Longer contact periods mostly result in more adsorption. The low adsorption by the $300 \mathrm{~g}$ and $500 \mathrm{~g}$ may also be attributed to shorter contact times. It is possible that the low temperatures coupled with the less contact time contributed to the low maximum adsorption capacities of the $300 \mathrm{~g}$ and $500 \mathrm{~g}$ experiment. (Alam, Saha, Akisawa, \& Kashiwagi, 2004) observed that cycles times longer than $500 \mathrm{~s}$ led to cooling capacity decline. This possibly indicates that equilibrium state was obtained several times during the cycles. Thus, the varied adsorption capacities of the zeolites.

The energy of adsorption is a measurable indicator of the affinity of the adsorbate to the adsorption sites. Generally, the energy of adsorption (Figure 8) decreases with increasing quantity of zeolites. This may be affected by contact time, the hydrophilicity of the zeolite - water pair, amount of adsorbate as well as pore sizes of the zeolite grains. The increasing amount of zeolite although loose grains, macroscopic diffusion was limited. The limitation of the diffusion can be at- tributed to the hygroscopic nature of zeolites (Auerbach, Carrado, \& Dutta, 2003). This causes zeolites to agglomerate and thus reducing the diffusion of zeolites below the surface. For the adsorption process to be successful, macroscopic diffusion into the particles should be high (Alam, Saha, Akisawa, \& Kashiwagi, 2004). A major drawback of using loose grains for adsorption processes is high resistance to heat and mass transfer (Freni, Dawoud, Bonaccorsi, Chmielewski, Frazzica, Calabrese, \& Restuccia, 2015). Although the loose grains allow for a high void faction between grains, heat exchange is limited. Heat exchange between the vessel and the adsorbent material as well as the thermal insulation properties of zeolites contribute to this limitation. Thus, to overcome these limitations, higher differential vapour pressure between the adsorber and condenser is required (Restuccia, Recuper, Cacciola, \& Rothmeye, 1988). It is also important to keep the sensible heat supplied to the system lower than that of the adsorption - desorption heat so as to maintain high heat -pump effect values.

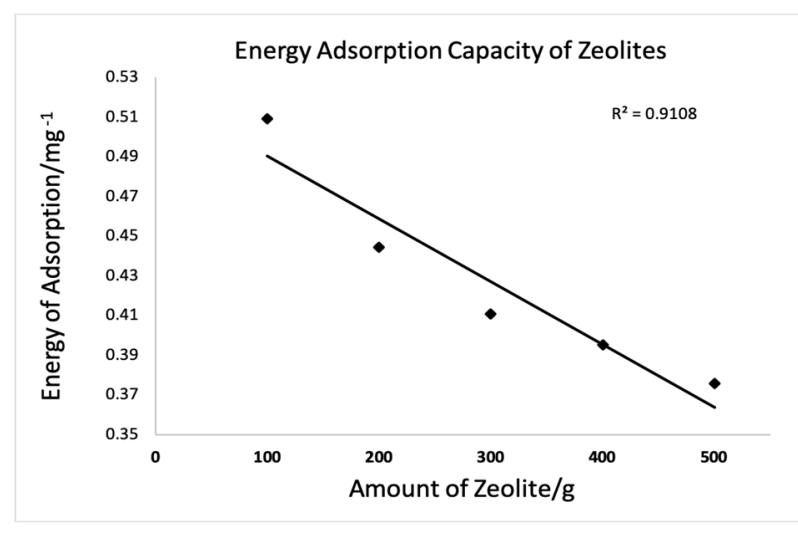

Figure 8. Energy of adsorption of various amounts of Zeolite A

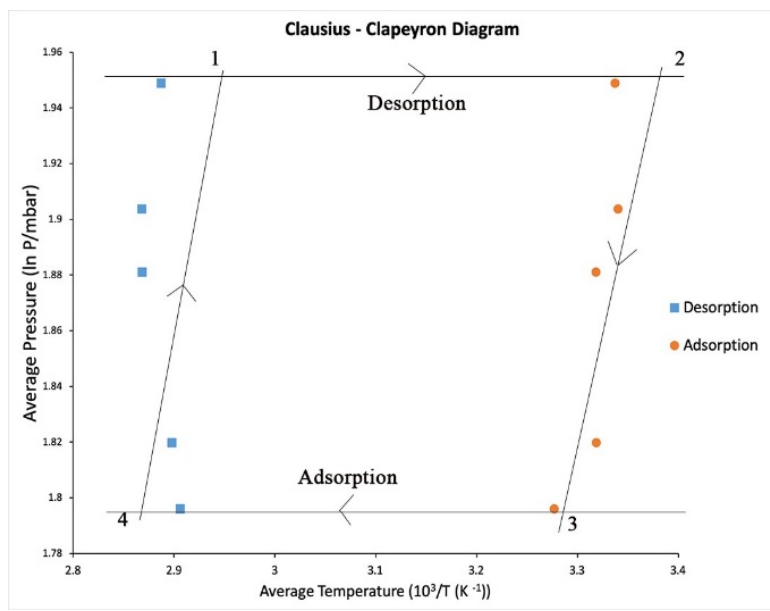

Figure 9. Extracted Clausius - Clapeyron Diagram showing adsorption - desorption cycle 
Using the average pressures and temperatures of the adsorption - desorption experiments, a Clausius - Clapeyron diagram was extracted (Figure 9). Isosteric cooling from the adsorption experiments show a more correlation than isosteric heating from the desorption experiments. Due to the batch experimentation, this data gives a general view of the system instead of the individual experiments conducted.

The use of a Stirling engine for heat recovery was studied by (Güven, Bedir, \& Anlaç, 2019) with 30\% additional useful energy generation when used with an internal combustion engine. Figure 10 shows the relationship between the power generated and the temperature of the hot cylinder of the Stirling engine. Power generated increases generally with temperature increase as in (Tchernev, 2001). The highest amount of power generated was $8 \mathrm{~W}$ with temperature around $120^{\circ} \mathrm{C}$. The power decreased with increasing time and temperature. This is attributable to the low cooling efficiency of the procured Stirling engine. Also observed was the higher rotation speed of the flywheel with increasing temperature as in (Shufat, Kurt, Cinar, Aksoy, Hançerlioğullari, \& Solmaz, 2019). As temperature increases, the vapour pressure contributes to the faster expansion of gases in the hot cylinder.

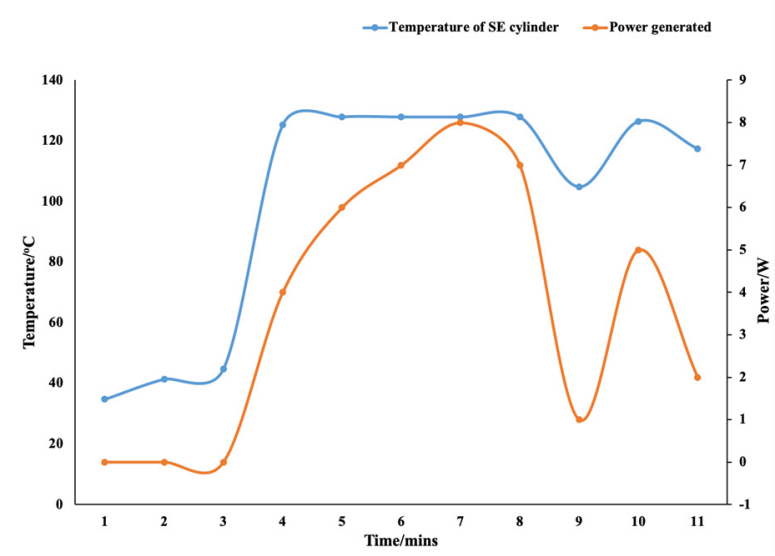

Figure 10. Amount of power generated using the stirling engine with respect to time and temperature

\section{Conclusion}

The results obtained indicates that zeolites synthesised from kaolin have the properties needed for TES applications. The use of thermal energy (solar or waste heat) in TES application can be enhanced with the use of a Stirling engine to generate electricity. The use of gaskets and other special materials can greatly reduce the loss of operational pressure of the system. This can also be used for waste heat recovery and power generation for small operations.

\section{Conflict of interests}

The authors declare that there is no conflict of interests regarding the publication of this paper.

\section{References}

Alam, K. C. A., Saha, B. B., Akisawa, A., \& Kashiwagi, T. (2004). Influence of design and operating conditions on the system performance of a two-stage adsorption chiller. Chem. Eng. Comm., 191, 981-997. https://doi.org/10.1080/00986440490276182

Aristov, Y. I. (2013). Challenging offers of material science for adsorption heat transformation: A review. Applied Thermal Engineering, 50, 1610-1618. https://doi.org/10.1016/j.applthermaleng.2011.09.003

Auerbach, S. M., Carrado, K. A., \& Dutta, P. K. (Eds.) (2003). Handbook of Zeolite Science and Technology. Marcel Dekker, Inc. https://doi.org/10.1201/9780203911167

Cacciola, G., \& Restuccia, G. (1995). Reversible adsorption heat pump: A thermodynamic model. Int. J. Refrig., 18(2), 100-106. https://doi.org/10.1016/0140-7007(94)00005-I

Chwieduk, D. A. (2012). Solar-assisted heat pumps. Comprehensive Renewable Energy, 3. https://doi.org/10.1016/B978-0-08-087872-0.00321-8 
Demir, H., Mobedi, M., \& Ülkü, S. (2008). A review on adsorption heat pump: Problems and solutions. Renewable and Sustainable Energy Reviews, 12, 2381-2403. https://doi.org/10.1016/j.rser.2007.06.005

Dicaire, D., \& Tezel, F. H. (2009). Study of adsorbent energy density and regeneration for long term thermal energy storage of solar and waste heat. Technical report, University of Ottawa, CANADA.

Dinçer, I., \& Rosen, M. A. (2011). Thermal Energy Storage: Systems and Applications (2nd ed.). John Wiley Sons, Ltd.

Fernandes, M. S., Brites, G. J. V. N., Costa, J. J., Gaspar, A. R., \& Costa, V. A. F. (2014). Review and future trends of solar adsorption refrigeration systems. Renewable and Sustainable Energy Reviews, 39, 102-123. https://doi.org/10.1016/j.rser.2014.07.081

Freni, A., Dawoud, B., Bonaccorsi, L., Chmielewski, S., Frazzica, A., Calabrese, L., \& Restuccia, G. (2015). Characterization of Zeolite-Based Coatings for Adsorption Heat Pumps. Springer. https://doi.org/10.1007/978-3-319-09327-7

Gougazeh, M., \& Buhl, J.-Ch. (2014). Synthesis and characterization of zeolite a by hydrothermal transformation of natural Jordanian kaolin. Journal of the Association of Arab Universities for Basic and Applied Sciences, 15, 35-42. https://doi.org/10.1016/j.jaubas.2013.03.007

Güven, M., Bedir, H., \& Anlaç, G. (2019). Optimization and application of stirling engine for waste heat recovery from a heavy-duty truck engine. Energy Conversion and Management, 180, 411-424. https://doi.org/10.1016/j.enconman.2018.10.096

Hoegel, B. (2014). Thermodynamics-based design of stirling engines for low-temperature heat sources. $\mathrm{PhD}$ thesis, University of Canterbury.

Jha, B., \& Singh, D. N. (2016). Fly Ash Zeolites, volume 78 of Advanced Structured Materials. Springer Singapore. https://doi.org/10.1007/978-981-10-1404-8

Kot, S. C., Hui, K. S., \& Chao, C. Y. H. (2005). Removal of mixed heavy metal ions in wastewater by zeolite 4a and residual products from recycled coal fly ash. Journal of Hazardous Materials, B127, 89-101. https://doi.org/10.1016/j.jhazmat.2005.06.027

Królicki, Z., Wilk, T., \& Zajaczkowski, B. (2006). Study on the efficiency of solar adsorption refrigeration and heat pump systems. In 61st ATI National Congress-International Session "Solar Heating and Cooling".

Kulprathipanja, S. (Ed.) (2010). Zeolites in Industrial Separation and Catalysis. WILEY-VCH Verlag GmbH Co. KGaA, Weinheim. https://doi.org/10.1002/9783527629565

Kumi, E. N. (2017). The electricity situation in ghana: Challenges and opportunies. Technical report, Center for Global Development, Washington DC.

Kwakye-Awuah, B., Labik, L. K., Nkrumah, I., \& Williams, C. (2014). Removal of arsenic in river water samples obtained from a mining community in ghana using laboratory synthesized zeolites. International Journal of Advanced Scientific and Technical Research, 4(4).

Mgbemere, H. E., Ekpe, I. C., \& Lawal, G. I. (2017). Zeolite synthesis, characterization and application areas: A review. International Research Journal of Environmental Sciences, 6(10), 45-59.

Restuccia, G., Recuper, V., Cacciola, G., \& Rothmeye, M. (1988). Zeolite heat pump for domestic heating. Energy, 13(4), 333-342. https://doi.org/10.1016/0360-5442(88)90028-X

Robson, H. (Ed.) (2001). Verified Syntheses of Zeolitic Materials, chapter Characterization by IR spectroscopy (2nd ed.). Elsevier Science B.V..

Scapino, L., Zondag, H. A., Bael, J. V., Diriken, J., \& Rindt, C. C. M. (2017). Energy density and storage capacity cost comparison of conceptual solid and liquid sorption seasonal heat storage systems for low-temperature space heating. Renewable and Sustainable Energy Reviews, 76, 1314-1331. https://doi.org/10.1016/j.rser.2017.03.101

Shufat, S. A., Kurt, E., Cinar, C., Aksoy, F., Hançerlioğullari, A., \& Solmaz, H. (2019). Exploration of a stirling engine and generator combination for air and helium media. Applied Thermal Engineering, 150, 738-749. https://doi.org/10.1016/j.applthermaleng.2019.01.053

Tchernev, D. I. (2001). Natural zeolites in solar energy heating, cooling, and energy storage. Reviews in Mineralogy and Geochemistry, 45(1), 589-617. https://doi.org/10.2138/rmg.2001.45.17 
van Hooff, J. H. C., \& Roelofsen, J. W. (1991). Studies in Surface Science and Catalysis, chapter Chapter 7 Techniques of Zeolite Characterization. Elsevier. https://doi.org/10.1016/S0167-2991(08)63605-8

Von-Kiti, E. (2016). Synthesis and characterization of zeolites from bauxite and kaolin: Application to the removal of heavy metals from mining wastewater. PhD thesis, Kwame Nkrumah University of Science and Technology.

Xu, R. R., Pang, W. Q., Yu, J. H., Huo, Q. S., \& Chen, J. S. (2007). Chemistry of Zeolites and Related Porous Materials: Synthesis and Structure. John Wiley \& Sons (Asia) Pte Ltd, 2 Clementi Loop \#02-01, Singapore 129809.

\section{Copyrights}

Copyright for this article is retained by the author(s), with first publication rights granted to the journal.

This is an open-access article distributed under the terms and conditions of the Creative Commons Attribution license (http://creativecommons.org/licenses/by/4.0/). 